\title{
Publicidade e mito
}

Malena Segura Contrera Universidade Presbiteriana Mackenzie Universidade Católica de Santos 


\section{Resumo}

O presente artigo propõe uma reflexão sobre a presença de recursos míticos na produção e no fazer publicitário de nossa sociedade. Aponta relações entre comunicação e cultura, situando a produção publicitária no universo dessas relações e apontando para o uso que a publicidade realiza de conteúdos míticos e de práticas de ritualização para evocar padrões de indentificação com o consumidor. Ressalta a distinção existente entre dois usos distintos para a palavra "mito", mostrando as diferenças básicas de sentido, natureza e intenção de cada uma dessas acepções. Sugere ainda a necessidade de uma maior seriedade no tratamento dado até então à questão de que as práticas publicitárias atuais ignoram, ou preferem ignorar, a dimensão ética no uso que fazem desses recursos míticos e rituais.

\section{Palavras-chave}

mito, publicidade, comunicação, cultura

\section{Abstract}

The current article propounds a reflection about the presence of mythical resources in the publicity producing and doings of our society. In addition, indicates the relations between communication and culture, setting the publicity production into the universe of these connections and pointing out the publicity use of mythical contents and ritualization practices to evoke identification patterns with the consumer. Moreover, emphasizes the distinction between the two distinct usages to the word "myth", showing the basic differences from sense, nature and intention of each meaning. Furthermore, suggests the necessity of a further severity in the approach concerning the issue that the current publicity practices overlook, or prefer ignore, the ethical dimension in the use done with these mythical and ritual resources.

\section{Key words}

myth, publicity, communication, culture 
$\mathbb{D}$

urante vários anos ministrei aulas e orientei trabalhos de conclusão nos cursos de Publicidade, Propaganda e Marketing, na área de Comunicação, em universidades de São Paulo, e quanto mais me detinha na análise do universo da comunicação contemporânea, mais era-me impossível não perceber a presença constante de aspectos míticos nas mais diversas situações e meios comunicativos: na telenovela e nos programas de TV em geral, no cinema, no jornal' e demais impressos, no rádio. E, como não poderia deixar de ser, já que se trata de uma prática comunicativa, na publicidade.

Uma das maiores contribuições que uma compreensão, mesmo que básica ${ }^{2}$, da mitologia e de como ela opera na publicidade pode nos trazer é a de não permitir que percamos de vista a complexidade e a riqueza do processo comunicativo e as mais profundas motivações que operam por detrás de técnicas e peças publicitárias específicas.

Afinal, foi buscando entender quais as motivações profundas existentes por detrás de algumas campanhas e situações publicitárias de sucesso, capazes de estabelecerem vínculos comunicativos eficazes na mobilização e influência da opinião pública, que acabei por deparar-me nessa área com um universo mítico por mim já conhecido. Seria impossível não tê-lo identificado.

1. A penetração dos mitos no universo da telenovela, do cinema e do jornal impresso já foi por mim analisada mais atentamente no livro O Mito na Mídia.

2. Este texto pretende enfocar o tema de forma introdutória, visto que foi feito para alunos de graduação e a eles se dirige. 
O próximo passo foi entender como esse universo mítico tem se reapresentado nas situações comunicativas sociais contemporâneas: os mecanismos de linguagem operados para que esse universo mítico irrompesse em toda a sua força e poder; poder que se torna sempre mais perigosamente "eficiente" quanto mais inconscientemente opera. Meus alunos e eu mesma, muitas vezes, nos surpreendemos muitíssimo com a situação dupla encontrada nesses casos, frente ao poder de se evocar o melhor e o pior de cada um de nós - e da sociedade em geral - quando se lança mão desses recursos míticos.

E quando transitamos por esse tema, sempre esbarramos em uma importante questão ética: quem cria essas peças publicitárias tem consciência de estar lidando com registros tão inconscientes e enraizados no homem e, até por isso mesmo, tão eficientes para a influência da formação de valores, de hábitos de consumo, da própria sociedade, enfim? A resposta pode ser sim e/ou não.

Contemporaneamente, e desde o surgimento e expansão da mídia eletrônica e da cultura de massas, surge um novo significado para a palavra mito; ele passa a ter duas acepções diferentes, com pontos comuns mas que se diferenciam em essência. Essa "dupla identidade" costuma causar um enorme mal entendido quando se fala de mito com não-especialistas.

Esse mal entendido ainda se agrava quando consideramos o fato de que há no mito propriamente dito uma ambivalência própria. É com muita pertinência que o psicólogo James Hillman (Entre-Vistas: 51) nos chama a atenção para o fato de que a linguagem mítica seja provavelmente cheia de paradoxos, de figuras de contradição para, entre outras coisas, evitar um certo literalismo nas interpretações que normalmente acarretaria um comprometimento das mais autênticas possibilidades de revelação de sentidos contidos no mito.

Isso leva-nos a pensar que esse caráter paradoxal da linguagem mítica presta-se especialmente bem à representação dos fenômenos complexos que não podem ser causalmente ou linearmente enfocados, servindo como uma forma de representação que evite esse literalismo que Hillman aponta como sendo o principal traço redutor e destruidor da riqueza imaginativa da psique.

Mas esclarecido o ponto de que não estamos falando dessa ambivalência interna e criativa do mito, há de fato em nossa socieda- 
de contemporânea, como já dissemos, duas acepções diferentes de mito. Vamos a elas.

\section{De mitologia e das mitologias}

Se perguntamos ao Novo Dicionário da Língua Portugue$s a$, de Aurélio Buarque de Holanda Ferreira, sobre o que é mito, encontraremos definições mais ou menos opostas. Agrupei essas definições aqui de forma a já apontar para as duas diferentes concepções usadas atualmente para mito:

1. Narrativa dos tempos fabulosos ou heróicos. 2. Narrativa de significação simbólica, geralmente ligada à cosmogonia, e referente a deuses encarnadores das forças da natureza e/ ou de aspectos da condição humana. 6. Representação (passada ou futura) de um estágio ideal da humanidade. 9. Filos. Exposição de uma doutrina ou de uma idéia sob forma imaginativa, em que a fantasia sugere e simboliza a verdade que deve ser transmitida. 10. Filos. Forma de pensamento oposta à do pensamento lógico e científico.

2. Representação de fatos ou personagens reais, exagerada pela imaginação popular, pela tradição, etc. 4. Pessoa ou fato assim representado ou concebido: Para muitos, Rui Barbosa é um mito. Sin., (relativo à pessoa) nesta acepção: monstro sagrado. 5. Idéia falsa, sem correspondente na realidade. 7. Imagem simplificada de pessoa ou de acontecimento, não raro ilusória, elaborada ou aceita pelos grupos humanos, e que representa significativo papel em seu comportamento. 8. Coisa inacreditável, fantasiosa, irreal, utopia.

De cada um dos dois grupos de definição, destaquei algumas partes, em específico as que, de certa maneira, representam a idéia geral das outras definições.

Como vemos, estamos diante de uma palavra que abriga idéias opostas: mito é uma narrativa simbólica que representa forças da 
natureza e aspectos da condição humana (o que o torna absolutamente relevante e revelador) mas é, ao mesmo tempo, imagem simplificada e redutiva, idéia falsa, irreal, no entanto aceita pelos grupos humanos influindo significativamente em seu comportamento (o que o torna ideologicamente muito suspeito).

Essa ambigüidade, na realidade, revela a própria cisão dissociativa pela qual o pensamento humano passou desde a época do nascimento do mito até os dias de hoje. Se inicialmente a capacidade imaginativa - mítica - era considerada legítima e reveladora de aspectos psicológicos e existenciais que através dela se faziam conhecer melhor, ao sujeitarmo-nos historicamente a um modelo de pensamento racionalista ${ }^{3}$, toda a criação da imaginação passa a ser mal-vista, autorizada "apenas enquanto arte" (como se a arte pudesse ser restritiva), ou reprimida e renegada à instância das patologias psicológicas.

Sobre esse descaso quanto aos processos imaginativos, o psicólogo James Hillman coloca:

E este concretismo desalmado domina tanto o projeto da bomba de nêutrons como a atitude terrorista, e isso mostra que eles partilham a mesma realidade arquetípica, a mesma insanidade. Ambos acreditam que o que existe de mais real são as estruturas externas e físicas. Concretismo desalmado. Acredito que o que há de mais real são as estruturas da consciência, da imaginação, de forma que quando as idéias se movimentam, quando a mente se movimenta, quando as imagens se movem, as outras coisas também se movem. (J. Hillman,1989, pp. 126-127)

Quando domina esse tipo de pensamento, que Hillman chama de "concretismo desalmado", a produção da imaginação e, con-

3. Essa questão é extremamente importante quando se pretende entender, com mais profundidade, as transformações históricas pelas quais o conceito de mito passa, seguindo um movimento maior de transformação do próprio pensamento humano. Para quem quer se aprofundar nessa questão, sugiro a leitura dos livros O Ponto de Mutação e A Teia da Vida, de F. Capra; bem como do livro O Erro de Descartes, de R. Damásio. 
seqüentemente, o pensamento mítico, passam a ser tão desautorizados e reprimidos que vemos uma situação na qual, como concluiu o fundador da psicologia profunda, Carl G. Jung, os deuses se tornam doenças.

Mas como nasce o pensamento mítico original, afinal? A que tipo de situação ou necessidade humana ele responde?

\section{Mito e origem - mito e arquétipo}

Por que somos tão ávidos por um mexerico, e por que a maledicência é tão grosseiramente rentável? O mexerico é, afinal, uma atividade primária de almas em confusão. Estas histórias exprimem a função mitopoética da psique ao nivel pessoal de contar histórias, de fabular. (J. Hillman, 1984, p. 34)

É pensando na força da fofoca que o psicólogo J. Hillman conclui que, mais do que fome de mexerico, o ser humano tem fome de histórias, de narrativas.

Isso explicaria muito do sucesso da indústria do boato, principalmente o boato que se utiliza dos meios de comunicação de massa, capazes de determinar eleições e fazer que o consumo de um produto se altere radicalmente. Quem não se lembra da maneira como uma emissora de TV brasileira praticamente elegeu um presidente para depois, invertendo todo o seu discurso, apoiar a sua interdição $0^{4}$ ?

Mas que necessidade humana tão grande de narrativas, de histórias, é essa que, na falta de coisa melhor, alimenta-se de boataria, de mexerico? Qual o papel que esse "contar histórias" desempenha, afinal?

O antropólogo da complexidade, Edgar Morin, ao falar sobre o surgimento do homo sapiens, sinalizando para o processo de emergência desse ser complexo que se diferencia dos outros hominídeos e que virá a constituir o que chamamos de espécie humana, refere-se com muita clareza ao papel da construção dessas estruturas de pensamento imaginativas que nascem como uma

4. O caso Fernando Collor de Melo. 
forma de resposta à consciência de suas próprias limitações quando o homem se depara com sua mortalidade.

$\mathrm{O}$ homem lança mão de recursos de linguagem, recursos cognitivos; sistemas de organização espaço-temporais por meio dos quais o homem vai organizando a realidade assimilada, especialmente significativos na medida em que são maneiras de organizar, através de uma ação imaginativa, questões que se apresentam especialmente angustiantes e geradoras de ansiedade no homem. Essa ansiedade é aqui entendida como decorrente e, ao mesmo tempo, agravante do surgimento de uma tomada de consciência do eu, da consciência de que somos entidades separadas do mundo na medida em que não somos mais inconscientemente ligados ao ambiente e às outras pessoas (como ocorre na relação bebê/mãe).

Ele diz, sobre essa ansiedade, que:

A ansiedade é produto, e também produtora da hipercomplexidade (do homo sapiens-demens). Ela vai estimular a curiosidade, e a pesquisa errante em todos os sentidos, da verdade que explica, da certeza que se esquiva, da felicidade que é devida, e esta pesquisa vai assumir uma dimensão espantosa. Vai, ao mesmo tempo, sustentar as crises e ser por elas sustentada. Vai estimular e alimentar os mitos, as magias, as religiões, que contrabalançam a demasiadamente grande incerteza do tempo, a demasiadamente grande angústia da morte. (Morin, 1988, p. 138)

Sobre o papel dos mitos nesse momento da irrupção da consciência e da ansiedade que a acompanha, Morin ainda coloca:

Portanto, tudo nos indica que o Homo sapiens é atingido pela morte como por uma catástrofe irremediável, que vai trazer consigo uma ansiedade específica, a angústia ou horror da morte, que a presença da morte passa a ser um problema vivo, isto é, que trabalha a sua vida. Tudo nos indica igualmente que esse homem não só recusa essa morte, mas 
que a rejeita, transpõe e resolve, no mito e na magia. (Morin, 1988, p. 95)

O pensamento mítico nasce como resultado da formação de estruturas cognitivas (narrativas, histórias) que possibilitem uma nova organização dos dados limitadores e angustiantes da realidade, uma nova organização que se dá na realidade imaginada.

Ou seja, o homem inicialmente desenvolve uma imensa capacidade imaginativa como uma forma de controlar uma situação de crise real e objetiva, utilizando para esse controle sua capacidade de criar uma outra realidade: a realidade da imaginação, da arte, do universo representado, da linguagem.

No processo de representação do mundo o homem transforma a realidade. Esse ato de transformação tem como objetivo primeiro sua necessidade primitiva de se apropriar e, de alguma maneira, "controlar" a situação, apaziguando sua angústia de modo a tornar possível sua sobrevivência.

Dessa forma, criar, representar, contar histórias não são um luxo reservado a poucos "eleitos" (os artista, os publicitários, os dotados etc.); é, sim, antes de mais nada, uma atividade que nasce com o próprio homem, uma necessidade surgida de uma luta básica pela sobrevivência.

Tornando-se um ser "imaginante", o espaço do seu imaginário acaba servindo como o palco da elaboração de muitos conflitos e crises antes insolúveis.

Essa dinâmica nos remete ao conceito de primeira e segunda realidades apresentado pelo semioticista da cultura Ivan Bystrina que propõe a classificação de dois tipos básicos de realidade: a primeira realidade, biofisioquímica; e a segunda realidade, simbólica, imaginativa e cultural (in Semiotik der Kurtur).

Vale sempre ressaltar que o próprio Bystrina chama-nos a atenção sobre não ser absolutamente possível dissociar a ação dessas "duas realidades" (categorizadas mais como um recurso metodológico para a apreensão desse processo do que como instâncias separadas e autônomas em si). Ou seja, vale lembrar o exemplo de O. Wells: se fôssemos informados, por uma mídia de grande 
credibilidade junto à opinião pública, sobre um ataque dos marcianos à Terra, antes mesmo de podermos constatar isso factualmente, ou de sofrermos na "pele da primeira realidade" esse ataque, muitos de nós talvez tivessem um enfarte ou coisa assim. Na realidade, neste caso, o que estaria nos matando não teria sido algo de origem concreta, já que o ataque só ocorrera de fato no universo da linguagem, da literatura, mas sim uma informação capaz de acionar todo nosso repertório imaginário de representações sobre o que significaria ser atacado por marcianos. O que nos mataria seriam nossas representações sobre o que foi informado, que acabariam gerando uma ação sobre o corpo, sobre o orgânico (o ataque cardíaco).

A medicina psicossomática já apresentou, e vem apresentando, com muita pertinência a efetividade dessa relação entre padrões de pensamentos e sentimentos e reações orgânicas; e toda a ciência contemporânea comprometida com uma visão mais complexa dos fenômenos sabe que essa divisão absolutamente não existe.

Pensando dessa forma, conseguimos entender o poder das representações e percebemos que, se por um lado uma imagem associada à destruição, vinda do nosso universo conceitual, pode gerar uma reação de crise orgânica (o enfarte), por outro lado, uma imagem associada à criação pode ser capaz de reorganizar, via imaginação, uma situação de crise orgânica (as histórias que contamos para acalmar alguém que está em crise). Claro que sempre devemos nos lembrar de estarmos atentos às devidas proporções, sabendo que nada é tão simples a ponto de podermos fazer transposições do tipo: se eu imaginar que não estou doente, estarei curado.

O risco de banalizar esse processo de formação das competências cognitivas e representativas da primeira e segunda realidades que levou milênios para se estabelecer no cérebro do sapiens (cf. E. Morin), essa relação entre real e imaginário, poderia nos tornar presas fáceis desse tipo de armadilha do pensamento com o qual muitas seitas, gurus e ideologias operam.

Cairíamos na armadilha do que J. Hillman aponta como o "literalismo proveniente da incapacidade simbólica"s.

5. Para quem deseja se aprofundar nesse ponto, sugiro a leitura das seguintes obras de James Hillman: Paranóia e Entre Vistas, ambas já publicadas no Brasil. 
Ao compreendermos que esse literalismo que Hillman chama de "paranóico" se aplica perfeitamente bem à nossa sociedade, entendemos o que faz com que, na maior parte das vezes, a publicidade possa operar satisfatoriamente com o raciocínio oposto a ele. Como todo extremo chama por seu oposto binário, e nos processos culturais encontra-se com muita freqüência esse padrão primitivo binário (bem/mal, tudo/nada, rico/pobre, amor/ódio), esse literalismo encontra seu oposto num processo simplista, porém eficiente, inverso ao literalismo: ao consumir tal produto você não consome o produto em si mesmo, consome toda a carga projetiva de valores que ele representa. $\mathrm{O}$ que consumimos é cada vez menos os produtos em si mesmos e cada vez mais os símbolos criados pela Publicidade e Propaganda ${ }^{6}$.

Interpretamos literalmente o que careceria de uma leitura simbólica, imaginativa, e, como conseqüência disso, cada vez mais nos tornamos incompetentes para ver no concreto o que realmente está lá. Literalizamos quando deveríamos interpretar; e abstraímos, virtualizamos, quando deveríamos estar atentos ao concreto (vivendo o corpo ao invés de consumir as imagens do corpo, por exemplo). Cada vez mais compramos - e vendemos - "gato por lebre", já que, afinal, não importa o que se compra, mas sim o que se acredita estar adquirindo, ou ainda o próprio gesto de comprar. Comprando, partilhamos do ritual do consumo que possivelmente seja, nas megacidades contemporâneas, um dos poucos rituais acessíveis e abrangentes.

Nesse caso, teríamos de estar atentos quanto ao risco das oposições simplificadoras: desconsiderar o poder da segunda realidade, do imaginário, das imagens, das histórias seria tão obtuso quanto atribuir a elas um poder absoluto. $\mathrm{O}$ segredo encontra-se exatamente em aprender a "ler" essa relação sempre peculiar que se dá entre o concreto e o imaginário em cada sociedade, em cada cultura, em cada caso (e em cada público).

6. O teórico da comunicação Jean Baudrillard apresenta esse processo em vários de seus livros, mas com especial clareza em O sistema dos objetos e $A$ sociedade do consumo, livros que recomendo para quem deseja se aprofundar nessa questão. 
Algumas dessas relações são mais gerais e universais; outras, mais específicas e particulares. Os mitos se encontram exatamente entre os padrões de relações universais.

Quem se dedica ao estudo da mitologia comparada vê muito claramente que se está lidando com um princípio universal. Esse princípio criativo que o mito traz em si desde o seu surgimento, ele mesmo surgindo como uma maneira criativa de lidar com as limitações da realidade orgânica, é universal não só porque é encontrado em diferentes culturas, mas também por se reapresentar em diferentes épocas. O mito é, por exemplo, posto em ação até hoje por nós quando sentimos a necessidade de criar "peças" comunicativas que encenem os conteúdos que nos atormentam ou nos ameaçam por serem decodificados/entendidos por nós como sendo perigosos. Isso lança uma luz sobre o fato do porque $90 \%$ dos temas abordados pelos meios de comunicação são mortes, catástrofes, tragédias, fome, miséria.

Mais do que apenas um gosto mórbido pela desgraça, ao fazer dessa desgraça seu principal tema, nossa sociedade midiatizada sinaliza o grau de sua insegurança e angústia. Quando algo nos incomoda terrivelmente tratamos logo de nos defender com histórias de todo tipo: prolongamos por meio dos tex tos que criamos o tempo de vida de quem terminou organicamente, ou seja, morreu. Exemplo claro desse mecanismo são os programas televisivos e os impressos "especiais" elaborados (e consumidos vertiginosamente) quando alguém de destaque morre (Airton Senna, Lady Diana, etc.) ${ }^{7}$. Parece que há nessa reação uma tentativa de inverter a morte por meio de uma ação imaginativa, contando-se histórias de todo o tipo sobre a vida dessas pessoas.

Sobre como o mito é gerado nessa inter-relação entre a primeira e a segunda realidades, a fala do mitólogo Joseph Campbell também é bastante clara:

Como os sonhos, os mitos são produtos da imaginação humana. Suas imagens, em conseqüência, embora oriundas da

7. Sobre como os jornais noticiam a morte, recomendo a leitura do trabalho de Milton Pelegrini, A morte informada. 
mundo material e de sua suposta história, são, como os sonhos, revelações das mais profundas esperanças, desejos e temores, potencialidades e conflitos da vontade humana que por sua vez é movida pelas energias dos órgãos do corpo que funcionam de maneiras variadas uns contra os outros, e em concerto. Ou seja, todo mito, intencionalmente ou não, é psicologicamente simbólico. Suas narrativas e imagens devem ser entendidas, portanto, não literalmente, mas como metáforas. (Campbell, 1991, pp. 49-50)

C. G. Jung dizia mesmo que "os mitos são os sonhos da cultura". E todos sabemos como nosso organismo reage fisiologicamente aos conteúdos de nossos sonhos enquanto sonhamos.

Outro conceito análogo ao de "padrões de relações" que poderíamos lembrar para entendermos melhor esse processo metafórico, psicologicamente simbólico, do qual Campbell fala, seria o de arquétipos.

A palavra arquétipo, do grego archétypon, etimologicamente significa: modelo de seres criados, padrão exemplar, protótipo. $\mathrm{Ou}$ seja, um tipo original, que, por estar na constituição primeira e básica do humano, aplica-se à espécie enquanto um todo.

C. G. Jung contribuiu enormemente para a ampliação do conceito de arquétipo, um dos pontos principais de toda a sua obra. Diz ele:

Os arquétipos são formas de apreensão, e todas as vezes que nos deparamos com formas de apreensão que se repetem de maneira uniforme e regular, temos diante de nós um arquétipo, quer reconheçamos ou não seu caráter mitológico. (Jung, 1986, p. 73)

E em outro momento:

... naturalmente não se trata de idéias hereditárias, e sim de uma predisposição inata para a criação de fantasias paralelas, de estruturas idênticas, universais da psique, que mais 
tarde chamei de inconsciente coletivo. Dei a estas estruturas o nome de arquétipos." (Jung, 1989, p. 145)

Jung chama a atenção para a relação existente entre arquétipo e mito e ressalta que não se trata de idéias hereditárias, deixando de lado qualquer visão determinista. Em outro momento ainda complementa sua visão de arquétipo ressaltando seu caráter imagético, vendo-o como "um modo de apreensão":

... a maneira pela qual o homem pinta internamente o mundo permanece, a despeito de todas as diferenças de detalhe, tão uniforme e regular como suas ações instintivas... ; para explicar a uniformidade e a regularidade de nossas percepções, temos de recorrer ao conceito correlato de um fator que determina o modo de apreensão. É este fator que chamo arquétipo ou imagem primordial. A imagem primordial poderia ser descrita adequadamente como a percepção que o instinto tem de si mesmo. (CW, VIII, 277 - citado por J. Hillman, 46)

Interessante ressaltar que, contrariamente a muitos pósjunguianos, Jung jamais fez uso banal desse conceito, utilizando-o como uma receitinha pronta para ser imposta ao objeto por ele observado. Ele chegou mesmo a aconselhar (in Sonhos, Memórias e Reflexões) que o psicólogo, e quem se vale de qualquer teoria psicológica, deveria estudar e conhecer todas as linguagens simbólicas arquetípicas que pudesse: a alquimia, a mitologia, etc.; mas que, ao estar frente a frente com um paciente, deveria "esquecer" tudo isso e olhar atentamente para seu paciente. Ou seja, respeitar as singularidades de cada caso.

Aproveitando esse conselho e transpondo-o para o universo da publicidade, teríamos algo assim: saiba tudo que puder sobre os conteúdos e técnicas da sua área, estude as campanhas bem sucedidas e entenda o que não deu certo nas campanhas que fracassaram, mas frente a um problema de comunicação, não se esqueça de por todo esse conhecimento a serviço do problema apresentado. Não 
faça jamais o contrário, não faça de um caso um pretexto para exibir seu suposto talento; coloque o seu talento a serviço do seu caso. E, para começar, "leia" atentamente o que o caso apresenta. Só partindo de uma correta leitura inicial de um caso pode se saber qual o desenvolvimento necessário para atingir o que se objetiva.

Isso presumiria que não se negligenciasse as etapas de pesquisa e planejamento de uma campanha, etapas que requerem uma boa competência de leitura do caso em questão, de seu histórico, de suas relações com o meio objetivo e ... imaginário. Sabemos que a cultura muitas vezes determina totalmente a aceitação ou não de um produto, de acordo com a maior ou menor capacidade que ele tenha de evocar conteúdos do imaginário, provocando ou não uma identificação do público consumidor. Afinal, o que não tem vínculos comigo não é capaz de me comunicar nada, e muito menos de provocar em mim uma resposta (e ainda menos o desejo que me leva a consumir).

Pode parecer banal, mas é só olhar a pasteurização e a obviedade (sem falar na ineficiência) de alguns trabalhos da área de comunicação para vermos que esse princípio de C. G. Jung não deve ser tomado por óbvio demais para merecer a atenção devida.

Há uma enorme quantidade de livros, palestras e woorkshops sobre a área de comunicação (especialmente Publicidade e Marketing) que propõem modelitos estereotipados de ação, receitinhas prontas que não apresentam a menor proposta de reflexão, a menor habilidade imaginativa para "ler" adequadamente os fenômenos da comunicação e da cultura.

A consciência de como a publicidade lida com esses padrões arquetípicos presentes no imaginário de uma cultura é uma questão ética da maior importância e talvez fosse adequado que, em algumas situações, um mitólogo ou especialista em comunicação e mitos fosse consultado, como fizeram S. Spielberg e G. Lucas com o mitólogo J. Campbell quando faziam o filme "Guerra nas Estrelas" (cf. O poder do mito). Afinal, se vou ajudar a vender um produto (seja ele um objeto, uma imagem ou uma ideologia), se vou colocar minha competência técnica e os meios dos quais disponho para levar as pessoas a consumirem esse produto, seria conveniente que, ao menos, eu estivesse consciente dos custos reais - e imaginais - dessa ação. 
E essa questão da relação custos/benefícios não só econômicos, mas também culturais de uma ação nos remete à segunda acepção de mito.

\section{Mito e estereótipo: a pasteurização contemporânea do mito}

Edgar Morin, em Cultura de Massas no Séc. XX, cita um fenômeno cultural que ele diz se encontrar nas raízes do consumo moderno - e, diríamos nós, da comunicação moderna e contemporânea. Ele afirma que a cultura de massas, para atingir seus objetivos e estender sua ação ao âmbito mais geral possível, influenciando a opinião pública na enorme escala pretendida, precisou encontrar uma forma de homogeneizar o gosto público que iria criar o consumo em escala adequado à nova forma de produção industrial em série.

Para formar esse novo gosto que sirva a esse objetivo:

... é possivel uma organização burocrático-industrial da cultura. Essa possibilidade reside, sem dúvida, na própria estrutura do imaginário. O imaginário se estrutura segundo arquétipos: existem figurinos-modelo do espírito humano que ordenam os sonhos e, particularmente, os sonhos racionalizados que são os temas míticos ou romanescos. Regras, convenções, gêneros artísticos impõem estruturas exteriores às obras, enquanto situações-tipo e personagenstipo lhes fornecem as estruturas internas. A análise estrutural nos mostra que se pode reduzir os mitos a estruturas matemáticas. Ora, toda estrutura constante pode se conciliar com a norma industrial. A indústria cultural persegue a demonstração à sua maneira, padronizando os grandes temas romanescos, fazendo clichês dos arquétipos em estereótipos. (Morin, 1990, p. 26)

Estamos lidando aqui com um outro conceito de mito: o da criação de tipos, os chamados mitos da mídia, criados a partir de 
uma estética do estereótipo da produção em série, com o objetivo de incentivar o consumo em massa.

Aqui temos uma situação que se dá a partir da cultura de massa: a noção de pertencência e participação cultural, fundamental para o sentido de identidade sociocultural, é substituída pelo consumo. Tenta-se continuar pertencendo ao grupo através da única ação partilhada possível, depois de extintos os rituais de participação e a relação com o mítico-religioso: a ação do consumo.

Mas por que essa necessidade aparentemente exagerada de pertencer ao grupo, mesmo que isso signifique consumir, consumir, consumir? Essa necessidade de pertencência aponta para a questãochave do processo que está por trás de toda a vida: a da formação de vínculos. Sem a formação de vínculos não há nenhuma possibilidade de comunicação em nenhuma instância de vida; dos microorganismos às sociedades, os vínculos são a premissa básica para a formação dos vasos comunicantes capazes de alimentar e manter vivo qualquer sistema.

Sobre o papel e a importância dessa "pertencência", dessa rede de ligações significativas que está no cerne de toda a vida, o etólogo Bóris Cyrulnik diz:

É preciso, pois, pertencer. Não pertencer a ninguém é não se tornar ninguém. Mas pertencer a uma cultura é tornar-se uma pessoa única...A pertença tem dois lados: a familiaridade e a filiação. A familiaridade é um sentimento que se experimenta e se reforça no cotidiano porque se enraíza na sensorialidade dos estímulos da vida doméstica. O sentimento de filiação, por sua vez, só existe na representação psiquica que se enraiza no contexto cultural. A familiaridade se alimenta de biológico, de memória e de sensorialidade cotidiana, ao passo que a filiação se alimenta de cultura. (Cyrulnik, 1995, p. 75)

Vivemos atualmente uma espécie de falência das experiências interpessoais cotidianas, que se tornaram aprisionadas por um modo de vida estereotipado (que limita as experiências pessoais mais 
particulares) típico das sociedades de massa. Isso resulta num enfraquecimento do sentimento de familiaridade que Cyrulnik cita. Não podemos ter familiaridade se nossas percepções sensoriais (os sentidos corporais) estão embotadas e nossa memória em crise.

Resta-nos, então, para sentirmo-nos pertencentes, coligados, o sentimento de filiação que se dá, na maioria das vezes, no gesto de compartilhar histórias, crenças, imagens (conteúdos do imaginário cultural), vinculando-nos ao universo simbólico criado pelos meios comunicativos que veiculam esses conteúdos. Acabamos, de fato, criando vínculos com os próprios meios: todos juntos assistindo às copas mundiais de futebol, através dos canais de tv que mostram as mesmas imagens no mundo todo.

O teórico da comunicação, Vicente Romano, chama-nos a atenção para um fenômeno moderno que esclarece um pouco a respeito de como a comunicação está relacionada à essa crise da familiaridade e das percepções sensoriais; a predominância cada vez maior do uso da mídia eletrônica na comunicação. A mídia eletrônica privilegia os sentidos à distância, ou seja, a visão e a audição, em detrimento de outros meios de comunicação que privilegiam os sentidos de proximidade corporal: o olfato, o tato, o paladar. É como se toda nossa herança religiosa judaico-cristã de culpa enfim nos convencesse da impureza e do pecado que o corpo representa. E nós, sem percebermos, damos prova de que concordamos com isso na medida em que acatamos cada vez mais a mídia à distância, os mundos encantados do virtual.

V. Romano nos apresenta essa situação, falando sobre a situação vigente nessa sociedade dos meios eletrônicos:

Lo atmosférico, el ambiente que convierte la expresión perfecta en acontecimiento, es irrepetible. Pero los medios técnicos de comunicación se orientan por la repetición. No trasmiten ningún contacto con la piel, ningún sabor ni olor, necesarios para la vivencia (Erlebnis). Sirven, satisfacen, a la vista y al oído, mientras que los otros sentidos perciben en el ámbito elemental... el lenguaje se somete a la ley de la economia de señales... La economia de señales es una cuestión de poder. El poder de unos seres humanos sobre otros se inicia con la 
incautación de biotiempo subjetivo de otros para los mensajes del comunicador. (Romano, 1993, p. 91$)^{8}$

Sobre a imensa possibilidade comunicativa do olfato, do tato e do paladar não nos compete falar nesse momento ${ }^{9}$, mas não podemos ignorar que certamente os sentidos da visão e da audição se prestam muito mais à natureza comunicativa dos meios eletrônicos e cibernéticos de comunicação de massa - viabilizadores da reprodução e da repetição. Um odor, uma textura, um sabor, são sempre singulares, intransferíveis, impossíveis de serem vivenciados sem uma proximidade corporal que possibilite e até mesmo exija uma espécie de atitude muito mais participativa do que a do consumo da sociedade de telespectadores na qual nos convertemos.

Frente à perda de identificação com o corpo individual e social, recorremos às estruturas do imaginário degradado do consumo:

Para Mongardini es la pérdida de identificación con las estructuras y los productos de nuestra cultura la que produce la polarización de lo mágico como unidad sustitutiva de lo real y orientada al sujeto, en vez de la unidad frágil, pero productiva, objetivamente constituida sobre un consensoidentificación... Puede decirse entonces que, en las relaciones sociales, el recurso a lo mágico aumenta en proporción directa con la distancia (psicológica, espacial, etc) y con la disgregación social. (Romano, 1993 pp. 103-104) ${ }^{10}$

8. "A atmosfera, o ambiente que converte a expressão perfeita em acontecimento, é irrepetivel. Mas os meios técnicos de comunicação se orientam pela repetição. Não transmitem nenhum contato com a pele, nenhum sabor nem cheiro, necessários para a vida ( Erlebnis ). Servem e satisfazem à vista e ao ouvido, enquanto que os outros sentidos percebem no âmbito elementar... Na imprensa, no rádio e na televisão, a linguagem se submete à lei da economia de sinais... A economia de sinais é uma questão de poder. O poder de alguns seres humanos sobre outros se inicia com usurpação de biotempo subjetivo desses outros para as mensagens do comunicador." (Tradução da autora)

9. Para um maior aprofundamento nesse assunto, recomendo as seguintes leituras básicas: Os Alimentos do Afeto, de B. Cyrulnik e Tocar, de A. Montagu.

10. "Para Mongardini, é a perda da identificação com as estruturas e os produtos de nossa cultura o que produz a polarização do mágico como unidade substitutiva 
No universo da publicidade esse "recorrer ao mágico" para possibilitar o sentimento de filiação, dá-se muito claramente na identificação com determinados produtos e com os grupos que se filiam a esses produtos: somos bebedores de cerveja, somos proprietários de carros da marca tal, somos fumantes do cigarro que nos traz liberdade, somos usuários da grife de roupas $\mathrm{x}$, somos freqüentadores dos lugares "certos" etc.

Vínculos são, portanto, simplesmente essenciais e indispensáveis. $\mathrm{E}$, na falta de vínculos concretos ou de vínculos imaginários mais autênticos e originais, valemo-nos das situações de vinculação dos "mitos midiáticos". Todos acompanhamos, juntos e vinculados, os rituais televisivos e cinematográficos de idolatria aos artistas do momento.

Estamos, portanto, filiados através dos meios de comunicação de massa que, pelo próprio tipo de códigos com os quais opera (os códigos dos sentidos à distância), não possibilitam uma maior vivência das percepções sensoriais concretas. E se as percepções sensoriais concretas não são matéria-prima dos meios eletrônicos de comunicação de massa, do que eles se alimentam?

Se retomarmos a observação de James Hillman sobre a "avidez por mexericos" com a qual abrimos nosso capítulo anterior, temos aí uma pista. Vemos a manipulação que os meios de comunicação de massa exercem sobre o grande público, garantindo assim a identificação necessária ao consumo, quando operam com imagens que eram originalmente míticas e arquetípicas. Ao submeter esses motivos a um processo de pasteurização, homogeneização e medianez/padronização" ${ }^{\prime \prime}$, impinge-se a esses motivos uma nova estética que opera a transformação do arquétipo em estereótipo. Acaba-se com a participação no sagrado (própria do mito original) para implantar a passividade voyeurista da idolatria, a cultura dos fãs (e o consumo de produtos a que isso leva).

do real, orientada ao sujeito; em vez de uma unidade frágil, mas produtiva, objetivamente construída sobre um consenso-identificação... Pode-se dizer, então, que, nas relações sociais, o recurso ao mágico aumenta em proporção direta à distância ( psicológica, espacial, etc ) e à desagregação social.."

11. E. Morin desenvolve com muita propriedade esse processo em seu livro Cultura de Massas no Sec. XX, vol. 1. 
O que era uma imagem arquetípica, então, é transformada (por meio da perda do todo, por meio da repetição imposta, das estereotipias, da perda da função integradora própria ao mito) em um produto padronizado, criado e ao mesmo tempo criador do que chamamos aqui de mitos midiáticos.

Mas como as imagens arquetípicas do inconsciente coletivo que povoam o imaginário cultural não são imagens das quais a sociedade possa livrar-se conscientemente (elas sempre voltam por mais recalcadas que sejam) ou das quais o grupo social possa prescindir (já que são o grande repertório cultural original), a sociedade contemporânea de massas, voltada para a estética do padronizado, produzido e vendido em larga escala, recolhe da vasta teia de relações do mito um ou outro elemento iconográfico, uma ou outra relação, um ou outro elemento temático, fragmentariamente, destruindo o contexto, eliminando exatamente essa noção de "teia" que caracteriza o mito. Opera-se a redução do mito original ao mito midiático.

Resultado: apresenta-se elementos suficientes para provocar a identificação do público, mas sem respeitar a relação desses elementos entre si e a composição do contexto primeiro, pondo a perder exatamente o caráter complexo, relacional e integrador do pensamento mítico.

Porém, como ocorre com o holograma, o mito muitas vezes encontra caminhos insuspeitos para, a partir de suas partes, evocar no receptor/consumidor a sensação do todo novamente. É como se os arquétipos encontrassem meios de se re-apresentarem, apesar de toda a pasteurização da estética da cultura de massas e dos meios de comunicação eletrônicos. Afinal, o caráter comunicativo que subjaz à própria natureza da mídia, por mais comprometida que ela esteja, resiste e sempre procura uma forma de permanecer. A permanência, aliás, é o primeiro princípio básico de todo sistema.

No entanto, não saberemos jamais ao certo quando essa recomposição hologramática ocorre e teremos sempre de recorrer a um estudo aprofundado sobre as formas de recepção para obtermos essa resposta que será, ainda assim, sempre passível de equívocos (e nessa equivocidade reside um dos grandes dramas das análises de opinião pública). 
Isso também torna muito difícil afirmar com certeza, quando surge um "novo mito" (do cinema, da música, do rádio, das mídias de massa em geral), de qual tipo de processo se trata. É preciso observar a reação da cultura frente ao que é apresentado e ver em sua reação se ele evoca uma ação integradora (havendo então uma predominância do arquetípico sobre a padronização), ou se ele evoca uma ação mimético-compulsiva, consumista, replicadora e homogeneizante (havendo nesse caso uma predominância da padronização sobre o arquetípico). Nesse último caso teríamos o chamado mito midiático.

No mito original, os arquétipos do imaginário cultural operam através de padrões universais, mas jamais são redutores. Os padrões universais são constantes, elementos que perduram no tempo histórico e que se encontram em diferentes culturas, sem no entanto negarem as diversidades regionais, os aspectos sociais, o meioambiente.

Já no mito midiático, apesar de podermos sempre identificar suas raízes em algum mito original depois perdido, a estereotipia redutora predomina, e a função principal é a de impor modelos a serem reproduzidos em grande escala; ele tenta impor suas máscaras exatamente às custas das diversidades regionais, das realidades ambientais e sociais. É a imagem de Carmem Miranda (ou da Xuxa ou da modelo que está em alta) representando a mulher brasileira para o mundo, a de Marilyn Monroe representando a mulher americana, a de Lady Di representando a mulher inglesa, e assim por diante. Falsos mitos construídos pelos meios de comunicação de massa que sobrevivem às custas do descaso pelas diversidades culturais.

São mitos feitos para aumentar a sensação de impossibilidade de quem os vive, ou de quem com eles entra em relação: nenhum ser humano consegue seguir o modelo dos superstars, ou os padrões estéticos vigentes propostos pela mídia. Basta vermos as síndromes de todo o tipo, que sinalizam esse descompasso entre o que somos e o que os padrões midiáticos e da moda nos intimam a ser: bulimias, anorexias, patologias várias em torno de graus diversos de perda de propriocepção (percepção e consciência de si mesmo) e identidade, próprias de nossa época. 
Tenta-se ser igual à tal modelo que, no entanto, é uma imagem; e, tal como é apresentada, não existe sem a mediação da indústria da mídia que se encarrega de realizar o truque do ilusionismo, fazendo tudo parecer possível de ser concretamente vivido, e convidando o grande público à essa realização através do consumo de todo o tipo de produto que carregue em si o símbolo do objeto desejado.

Carentes de vida simbólica, embarcamos no primeiro barco furado, usando como passaporte os cartões de crédito, e, incapazes de abrir mão do desejo e da necessidade de simbolização (traço fundamental do ser humano) consumimos os símbolos que estão à nossa disposição. Abrimos mão do concreto, transformamos nossos corpos em imagens, "des/encarnamos", numa cadeia de imagens e simulações que não se originam na natureza simbólica do homem, e sem das demandas e modismos do mercado.

Não podemos esquecer, no entanto, de um fator muito importante: o mito precisa ser rememorado para não perder sua validade, todo mito só sobrevive através do ritual.

\section{Os ritos modernos do consumo}

Quando nos propomos a estudar o pensamento mítico deparamo-nos necessariamente com os rituais, já que uma das funções específicas do ritual (re-atual) é a de re-memorar o mito, mantêlo vivo por meio de procedimentos e situações que vão dos mais festivos aos mais sóbrios, mas que têm como característica básica o fato de serem partilhados, de repetirem-se ciclicamente, regularmente, e de possuírem toda uma organização interna.

Sobre o papel do ritual para a vida e para a comunicação, o etólogo Bóris Cyrulnik afirma:

É o ritual que estrutura a comunicação entre dois organismos, duas pessoas ou dois povos diferentes. Esse ritual pode ser descrito em termos etológicos como um verdadeiro 'intermediário' sensorial, que permite harmonizar os corpos, comunicar emoções e trocar idéias. (Cyrulnik, 1995, p. 102) 
No mito original essa repetição cumpre a função de assegurar a permanência dos conteúdos expressos pelo mito, já que se crê que esses conteúdos nunca estão dados definitivamente, mas sim que estão acontecendo continuamente, através da participação do ser humano na construção e na manutenção de sua existência. $O$ mito carrega imagens que não sobrevivem sem que se volte a imaginálas periodicamente, ritualmente. $\mathrm{O}$ mito se alimenta dessa rememoração que mais do que uma participação passiva do indivíduo, como vemos hoje nos espetáculos em que só se participa virtualmente (o corpo permanece não-participativo, anestesiado), precisa de uma participação ativa cujas atividades principais são alimentar sua relação com o contemporâneo, seus vínculos com o momento presente e organizar a complexa psique humana.

Afinal, se ninguém se lembra de um mito é porque ele já não cumpre mais seu papel central que é o da representação simbólica das questões humanas mais fundamentais; ou seja, ele perdeu exatamente sua principal função, a de ser metáfora de alguns aspectos da vida. Se foi esquecido é porque é uma metáfora que não serve mais, porque não se presta mais à elaboração de aspectos da realidade que precisam ser apropriados/transformados simbolicamente pela consciência do homem.

É certo dizermos que os conteúdos atuais da mídia e da publicidade são exatamente as novas metáforas capazes de representar as questões mais atuais, mas seria uma ingenuidade mortal não perceber que esses novos "textos" desempenham esse papel de forma muito diferente do que os mitos originais o fazem. Basta observar quanto de participação ativa realmente consciente há nos "rituais modernos" de comunicação e de consumo.

Seria mesmo correto dizer que o traço mais essencial do pensamento mítico original que permanece na mídia e na publicidade é principalmente essa repetição, essa regularidade, mimese redutora do ritual.

Só que na comunicação de massas contemporânea, essa repetição não serve exatamente aos aspectos participativos e integradores dos mitos. A publicidade, por exemplo, vale-se sempre dessa regularidade, que tem por função gerar a criação de um hábi- 
to, para implantar uma marca, um produto, uma imagem qualquer junto ao mercado, e nem sempre realiza isso de modo responsável. Sabemos que o hábito é uma segunda natureza, portanto, para impormos um valor ou criarmos uma necessidade junto ao público consumidor, nada melhor do que sermos regulares: re-apresentarmos milhões de vezes aquilo que todos parecem já saber. Agindo assim, mais do que afirmar sua marca, a Coca Cola, por exemplo, re-atualiza-se e mantém seu feudo no universo do imaginário de uma cultura. E a participação real que está presente no ritual genuíno é substituída pela audiência (consumo imaginal e ideológico) ou pela ação do consumo (de bens concretos).

Quando sabemos da função da repetição e da importância do hábito, entendemos melhor porque somos tão refratários a mudanças estruturais nos meios de comunicação. A telenovela das 20:00 horas, aqui no Brasil, tem de continuar se chamando assim mesmo que vá ao ar quase sempre depois das 21:00 horas. O jornal impresso não pôde até agora mudar suas características físicas (seu suporte papel, seu formato, sua textura etc.), mesmo com os custos do papel cada vez mais exorbitantes e não sendo exatamente prático de se manusear. E o Silvio Santos está a frente de seu programa de tv todos os domingos "religiosamente" há décadas, como em uma missa de domingo.

Ai está a questão central com a qual a comunicação de massas opera: se o que é mítico precisa de ritualização para permanecer, seguindo esse princípio, o que se repete e permanece se legitima e se mitifica. Não importa se não temos algo que possa ser considerado notícia de fato para relatar, o jornal tem de sair todos os dias. Não se questiona a qualidade de uma marca que está presente na memória de uma sociedade há 50 anos; e não é incomum as pessoas pedirem aos comerciantes produtos que já saíram de linha há alguns anos, mas dos quais lembraram o nome quando recorreram à memória para escolher uma marca de um produto que usualmente não usam (isso acontece muito com xaropes e pomadas exaustivamente anunciados no rádio e que são pedidos nas farmácias mesmo depois de já não serem mais fabricados há anos).

"Falem bem ou mal, mas falem de mim" é uma filosofia muito adotada por políticos que sabem que mais do que serem con- 
siderados bons ou maus políticos pela opinião pública, é fundamental que sejam identificados e que permaneçam "memoráveis"; tenha esse memorável o sentido que tiver, é sempre melhor do que ser esquecido (por isso a obsessão de colocarem seus nomes em todas as pontes, viadutos, etc. que puderem). O esquecimento, no universo do mito e da comunicação (e da publicidade), significa a morte, a perda da função vinculadora. Afinal, não posso me vincular a algo que não reconheço, do qual minha memória não tem registro. E se não posso me vincular, não legitimo e não me identifico com esse algo, portanto, também não irei de modo algum comprá-lo e levá-lo para a minha casa e nem agregá-lo à minha imagem pública.

Esse é um dado com o qual a propaganda e a publicidade parecem muitas vezes trabalhar até mesmo intuitivamente. Mas a tão festejada intuição, nesse caso, não basta. Creio que seja muito relevante para a sociedade, em nossa época histórica de mudanças radicais que clamam por maior consciência sistêmica ${ }^{12}$ de nossas ações e de nosso papel no mundo, que as universidades e os cursos de formação profissional tomem para si o papel de discutir essas questões, trazendo ao plano das discussões conscientes e das opções éticas essas práticas muitas vezes "intuitivas" que fazem com que um "profissional de sucesso" (leia-se dinheiro), que domina a prática da área, seja visto com mais bons olhos do que um pesquisador sério, preocupado em alertar para os custos humanos de algumas práticas.

Creio que essa divisão entre a reflexão teórica e a prática profissional que até então vem acontecendo muito na área da Propaganda e da Publicidade (e do Marketing) em nosso país jamais foi justificável, e está cada vez mais condenada nesse momento que vivemos, no qual mais do que ser um profissional de sucesso, carecemos de profissionais que reavaliem constantemente a dimensão ética de suas escolhas, que sejam agentes conscientes de sua interferência e contribuição na criação de um ambiente comunicativo que

12. Para quem queira ampliar suas reflexões a respeito dessa questão e desse caráter sistêmico ao qual me refiro, sugiro a leitura de Edgar Morin, Fritjot Capra, e demais autores ligados ao paradigma da complexidade. 
privilegie e promova a tão anunciada (e tão pouco realizada) qualidade de vida.

Talvez sucesso e prosperidade não possam ser medidos exclusivamente por valores monetários. Sobre isso gostaria de propor uma reflexão sobre a absolutização do dinheiro em nossas vidas, traço que vemos contemporaneamente em nossa sociedade e que foi herdado de décadas e décadas de capitalismo. Gosto muito do que fala James Hillman sobre o valor das coisas; diz ele:

A linguagem econômica usurpou todos os termos que a alma usa para expressar riqueza e qualidade - valor, beneficio, crédito, vínculo, ativo e passivo, e assim por diante." (Hillman, 1989, p. 177)

Quando uma sociedade perde o sentido de todos os valores, incluindo o valor dos vínculos comunicativos, o único tipo de valor que resta é aquele que se estipula monetariamente. E esse quadro me parece muito deprimente, já que não sei se podemos desejar viver em um mundo no qual os únicos valores são a visibilidade e o enriquecimento.

\section{Bibliografia}

BAITELLO JR., N. 1997. O animal que parou os relógios. São Paulo: Annablume.

BAUDRILLARD, J. 1991. Simulacros e simulação. Lisboa, Portugal: Relógio D’água.

1995. A sociedade de consumo. Lisboa: Elfos.

CAMPBELL, J. 1992. As máscaras de Deus. S. Paulo: Palas Athena.

1992. As transformações do mito através do tempo. São Paulo: Cultrix.

1994. A imagem mítica. Campinas: Papirus.

CANETTI, E. 1995. Massa e poder. São Paulo: Cia. das Letras. 
CAPRA, F. s/d. Sabedoria incomum. Círculo do Livro. 1991. O ponto de mutação. São Paulo: Cultrix. . 1997. A Teia da vida. São Paulo: Cultrix \& Amana-Key.

CASTRO, G. et al.(coord.) .1997. Ensaios de complexidade. Porto Alegre: Sulina.

CONTRERA, M. S. 1996. O mito na mídia. 2.ed. 2000. São Paulo: Annablume.

CYRULNIK, B. 1995. Os alimentos do afeto. São Paulo: Ática. DURAND, G. 1995. A imaginação simbólica. Lisboa: Ed. 70.

ELIADE, M. 1972. Mito e realidade. São Paulo: Perspectiva. . s/d. O Sagrado e o profano. Lisboa: Livros do Brasil. 1978. Aspectos do mito. Lisboa: Vega. 1985. O mito do eterno retorno. Lisboa: Ed. 70. . 1991. Imagens e símbolos. São Paulo: Martins Fontes. HILlMAN, J .1989. Entre-Vistas. São Paulo: Summus. . (org.). s/d. Encarando os deuses. São Paulo: Cultrix/Pensamento.

HILLMAN, J. e VENTURA, M. 1995. Cem anos de psicoterapia... e o mundo está cada vez pior. São Paulo: Summus.

LOVELOCK, J. 1991. As eras de gaia: a biografia da nossa terra viva. Rio de Janeiro: Campus.

MAFFESOLI, M. 1996. No fundo das aparências. Petrópolis: Vozes.

MALRIEU, P. 1996. A construção do imaginário. Lisboa: Inst. Piaget. MORAIS, R. de (org.) .1988. As razões do mito. São Paulo: Papirus. MORIN, E.s/d. O método. 4 vols. Lisboa: Europa-América. . 1985. O paradigma perdido. Lisboa: Europa-América . 1986. Para sair do séc. XX. Rio de Janeiro: Nova Fronteira. 1990. Cultura de massas no séc. XX. Rio de Janeiro: ForenseUniversitária.

1990b. Ciência com consciência. Lisboa: Europa-América. 


\section{Piaget.}

1995. Introdução ao pensamento complexo. Lisboa: Inst.

1998. Ética, solidariedade e complexidade. São Paulo: Palas Athena.

ROMANO G., V. 1998. La formación de la mentalidad sumisa. Madrid: Endymion.

TODOROV, T. 1996. A vida em comum. Campinas: Papirus.

TURNER, V.W. 1974. O processo ritual. Rio de Janeiro: Vozes.

Site consultado

www.cisc.org.br (links biblioteca e Revista Ghrebh - textos de Norval Baitello Júnior, Dietmar Kamper e Vicente Romano; e textos do seminário Imagem e Violência) 